\title{
O Grupo Multifamiliar em Parceria com a Ação Psicossocial Forense
}

\author{
Maria Alexina Ribeiro \\ Universidade Católica de Brasília \\ Liana Fortunato Costa \\ Universidade de Brasília \\ Maria Aparecida Penso \\ Tânia Mara Campos de Almeida \\ Heron Flores Nogueira \\ Universidade Católica de Brasília
}

\begin{abstract}
RESUMO
Esta pesquisa buscou conhecer as possibilidades de integração entre o estudo psicossocial forense (subsidia decisões judiciais) e o encaminhamento de famílias para atendimento terapêutico. Objetivamos compreender quais sentidos são produzidos no trabalho conjunto, entre o profissional do setor psicossocial e a equipe que atende e supervisiona a intervenção terapêutica. $O$ método foi o qualitativo, os sujeitos foram oito profissionais do setor psicossocial de um tribunal de justiça, sendo três assistentes sociais e cinco psicólogas, com idades entre 28 e 60 anos e atuação profissional psicossocial entre 3 e 35 anos. O instrumento foi uma entrevista semiestruturada e a análise das informações foi numa perspectiva construtiva-interpretativa. Os resultados mostram sentimento de alívio por parte das profissionais em poder encaminhar as famílias; a necessidade de comunicação fluida entre a equipe que oferece atendimento e o setor psicossocial e de construção de oportunidades de interação entre os sujeitos jurídicos e não jurídicos.
\end{abstract}

Palavras-chave: psicologia clínica; grupo multifamiliar; psicologia jurídica.

\begin{abstract}
The Multi-familiar Group in Partnership with the Forensic Psychosocial Action

This research aimed at knowing the possibilities of integration between the forensic psychosocial study (which informs judicial decisions) and the submission of families for therapeutical attendance. We sought to understand which meanings are produced in the joint work between the psychosocial sector professional and the team that attends and supervises the therapeutical intervention. Qualitative methods were used wherein the subjects were eight professionals of the psychosocial sector of a court of law, with three being social assistants and five psychologists, aged from 28 to 60 years old and psychosocial professional experience between 3 and 35 years. The instrument used was a semistructured interview and the analysis of the information was under an interpretative constructive perspective. The results show a feeling of relief by the professionals for being able to submit these families; the need of a fluid communication between the team offering the attendance and the psychosocial sector and also of the creation of opportunities of interaction between the judicial and non judicial subjects.
\end{abstract}

Keywords: clinical psychology; multi-familiar group; judicial psychology.

A pesquisa original da qual este texto procede buscou conhecer as possibilidades de integração entre o estudo psicossocial, realizado no âmbito da Justiça e que subsidia as decisões do juiz sobre casos de violência contra crianças e adolescentes e o encaminhamento deles para atendimento terapêutico em instituição fora do âmbito da justiça, a partir deste estudo. Estamos nos referindo ao estudo psicossocial realizado com famílias nas quais ocorreu abuso sexual, onde o encaminhamento se faz a um Grupo Multifa- miliar (GM), baseado em um convênio entre um tribunal de justiça e universidades. Muitas são as questões presentes nesse contexto de encaminhamento e atendimento que necessitam serem compreendidas, para que seja efetiva a decretação da medida de proteção à pessoa violentada e a sua continuidade oferecida pela intervenção terapêutica. Dentre elas, situa-se a discussão sobre as questões de envolvimento emocional dos profissionais que atendem nos serviços psicossociais forense de Vara de Família. 
A questão do abuso sexual de crianças e/ou adolescentes em contexto intrafamiliar é uma problemática que cada vez mais vem a público. Com o advento da denúncia anônima esse tipo de conflito, que acaba mais restrito à vida privada, vem sendo também muito mais encaminhado ao contexto judicial. Em países de primeiro mundo, o atendimento terapêutico nesse contexto é realizado "sob obrigação". As famílias, que passaram por um estudo psicossocial forense, não apresentam demandas e são encaminhadas "sob obrigação" a procurarem um terapeuta, além disso não possuem condições econômicas para se locomoverem até consultórios e/ou instituições, estão traumatizadas e buscam mais esconder os acontecimentos do que expô-los. Como então viabilizar e descrever um modo de um possível encaminhamento mais efetivo? Como estruturar uma parceria na qual haja comunicação e continuidade entre o estudo psicossocial e a intervenção terapêutica? Em função da nossa parceria no atendimento a estas famílias e das observações de como se processa esta aproximação, temos procurado conhecer mais profundamente essa interface de atribuições entre a Psicologia e o Direito, a partir de pesquisas sobre a participação dos diferentes atores sociais envolvidos: operadores do Direito, famílias, alunos e professores de psicologia e profissionais do serviço psicossocial que são o nosso foco de análise neste artigo.

\section{O trabalho psicossocial no contexto da justiça}

O trabalho do psicólogo e do assistente social no contexto da Justiça tem sido cada vez mais respeitado e reconhecido por parte dos magistrados que dele se valem para complementar suas sentenças, em função dos saberes específicos que colaboram na busca de uma resolução menos destrutiva em casos de disputas de guarda e conflitos familiares violentos (Lima, 2003). Fávero, Melão e Jorge (2005) afirmam que, referindo-se ao trabalho de assistentes sociais e psicólogos do Tribunal de Justiça do Estado de São Paulo, o reconhecimento formal dessas duas áreas se configurou não somente pela necessidade de intervenção nas questões da esfera judicante, mas também em outros espaços desta instituição, ampliando-se as suas possibilidades de atuação. Os assistentes sociais, ao serem absorvidos no âmbito da justiça infanto-juvenil, passaram a atuar prioritariamente como peritos, em situações relacionadas à criança, aos jovens e às famílias, com vistas a oferecer subsídios à autoridade judiciária para a tomada de decisão. Segundo Ramos e Shine (1999) a ocupação do cargo de psicólogo, nos tribunais, tem visado o atendimento a menores da Vara da Infância e da Juventude e aos Juízes da Vara de Família. Por ter uma história tão curta, este entrecruzamento entre duas áreas do conhecimento, a Psicologia e o Direito, os autores se referem a algumas dificuldades nesta parceria, como a pouca clareza quanto ao trabalho do psicólogo neste contexto, o que pode causar certa insegurança dos profissionais. Para Ramos e Shine (1999) pela especificidade e pela inserção institucional, o psicólogo está numa encruzilhada entre uma ética do cuidado (ideal terapêutico) e a lógica da Justiça (produção da verdade).

Haley (1998) refere-se à "terapia compulsória", que é a união da terapia com o controle social, "com o Estado usando terapeutas para reformar desordeiros nestes tempos de crescente desordem" (p. 204). Os clientes, por sua vez, respondem ao terapeuta como um agente do Estado (mesmo que não seja assim), inseguros quanto ao que pode revelar sobre suas atividades ilegais, com medo de que o terapeuta revele essa informação ao tribunal. Para este autor tal postura representa uma contradição, uma vez que a terapia foi criada para ajudar pessoas que procuram auxílio voluntariamente e as escolas terapêuticas estão fundamentadas na ideia de que o cliente vem à terapia voluntariamente.

$\mathrm{Na}$ realidade brasileira, os profissionais e pesquisadores da área de Psicologia Jurídica, têm se debruçado sobre esta questão e vêm pensando formas de romper com o circulo vicioso do cliente que se apresenta para atendimento terapêutico sem apresentar demanda para tal. Dentre estes autores, citamos Sudbrack (2003) que há 20 anos desenvolve pesquisas na área de adolescência e uso de drogas, e defende a possibilidade de motivação de adolescentes e suas famílias para o trabalho psicossocial, numa perspectiva denominada por ela como "da obrigação à demanda, do risco à proteção e da dependência à liberdade". Nesta mesma linha de intervenção, outros autores têm desenvolvido propostas de trabalho com clientelas que não apresentam demanda explicita (Penso, Gusmão \& Ramos, 2003; Penso, Ramos \& Gusmão, 2005; Xaud, 2000).

Apesar dos avanços, na nossa experiência, observamos que situação de obrigação de atendimento coloca o psicólogo em um paradoxo do tipo: "vocês não são obrigados a vir até aqui para participar dos encontros, mas não se esqueçam de que o Juiz os encaminhou". No entanto, nosso entendimento é de que a obrigatoriedade da participação do indivíduo, grupo ou família, encaminhados para tais atendimentos, não impede o engajamento e investimento necessários 
para que os objetivos propostos sejam atingidos, além de representar uma obrigatoriedade em relação a uma criança e/ou adolescente que se encontra em situação de vulnerabilidade e desproteção física e psíquica. Talvez exija mais do terapeuta ou coordenador que deverá ser competente o bastante para motivar, envolver e transformar essa obrigação em demanda, assim como em responsabilidade frente ao bem-estar e o futuro das crianças e dos adolescentes, como nos casos de violência sexual para os quais nos voltamos especificamente.

Além da "obrigatoriedade" de acompanhamento psicológico - que legalmente só está prevista no Estatuto da Criança e do Adolescente (Brasil, 1990) quanto se trata da aplicação das medidas pertinentes aos pais e responsáveis, artigo 129, incisos II e III, que prevê a autoridade do Juiz no sentido de incluí-los em programas de tratamento - , outra questão que tem sido discutida no âmbito da pesquisa e do trabalho com vítimas de abuso sexual são as transformações que vêm ocorrendo na Justiça enquanto instituição, que está constantemente sendo desafiada por diversos fenômenos complexos que têm aparecido em seu âmbito. Tais fenômenos têm implicação em aspectos familiares, sociais, culturais, criminais, entre outros, e isso tem exigido dos profissionais que trabalham nesta instituição posturas mais flexíveis, interconectadas e abertas ao diferente e ao novo. No que concerne ao trabalho dos profissionais da Justiça, há uma percepção diante dos conflitos apresentados a estes profissionais sobre a necessidade de se repensar essa função, ampliando-a também a uma intervenção educadora e promotora de mudanças (Ribeiro, 2003).

\section{O Grupo Multifamiliar para famílias encaminhadas pela Justiça}

Iniciamos a mencionada parceria em 2001, caracterizada pelo atendimento contínuo de famílias em situação de violência e vitimização sexual, a partir do encaminhamento pelo Setor Psicossocial do Tribunal de Justiça do Distrito Federal e Territórios (TJDFT). A parceria se justifica perante o tripé de eixos norteadores da universidade: ensino, pesquisa e extensão. No período de 2002 a 2005 atendemos a quase 50 famílias. Os GMs são oferecidos duas vezes por ano, sendo que cerca de 10 famílias são encaminhadas para cada GM, porém, são de fato atendidas, uma média de 6 famílias em cada GM. As famílias possuem baixa renda (um a dois salários mínimos), moram em assentamentos, invasões, lixões e loteamentos em péssimas condições de sobrevivência, a maioria dos adultos possui apenas o primeiro grau incompleto. Muitos de seus membros são imigrantes e encontram-se desempregados, vivendo uma intensa situação de exclusão social. Após o término de cada GM, há uma devolução do desenvolvimento do grupo aos profissionais do Setor Psicossocial que fizeram os encaminhamentos, no sentido de informar os ganhos e limites do GM, em função da necessidade de realimentar, ou não, os parâmetros de proteção às crianças e adolescentes vitimizados. Esta parceria tem sua configuração em uma pesquisa-ação que viabiliza o oferecimento da metodologia do GM, e acolhe questões de pesquisas com os vários sujeitos que dela participam: famílias, crianças, adolescentes, alunos do Curso de Psicologia, professores supervisores, profissionais da Justiça, voluntários integrantes de outras instituições que estão sendo treinados para replicarem o GM.

O Grupo Multifamiliar fundamenta-se nos aportes teóricos: a) da Psicologia Comunitária, visando o trabalho em equipe com diferentes saberes, científicos e populares (Santos, 1999) e o enfoque da Psicologia Social Crítica e Histórica (Lane \& Sawaia, 1995) percebendo o ser humano em construção, que é constituído e constitui o meio em que se insere; b) da Terapia Familiar, tendo a visão de família enquanto sistema, sendo a relação o ponto focal do trabalho, priorizando o interpsíquico, não o intra-psíquico, e utilizando os recursos sistêmicos como a circularização e provocação (Minuchin, Colapinto \& Minuchin, 1999); c) do Sociodrama, em que o grupo é o protagonista e as famílias possuem objetivos comuns, além de se identificarem mutuamente (Moreno, 1993); e d) da Teoria das Redes Sociais que enfoca a interação humana com a troca de experiência, desenvolvendo a capacidade auto-reflexiva e auto-crítica (Sluzki, 1996).

O GM é planejado para ocorrer em 5 encontros com intervalo quinzenal, e o processo tem três etapas bem definidas: a) entrevistas com as famílias para definição da situação jurídica, definição de quem será convidado a participar; b) os encontros do GM que tem a duração aproximada de 2 meses e meio; c) avaliação das mudanças ocorridas nas interações familiares com relação ao restabelecimento das condições de proteção para crianças e adolescentes, e a consequente tomada de decisão de outras providências junto aos órgãos da Justiça, como, por exemplo, o Conselho Tutelar.

O GM se insere na perspectiva da Justiça Restaurativa (Pinto, 2005) constituindo-se numa nova abordagem conceitual do Direito, que se interessa mais pelo curso do processo em cada pasta jurídica, pela 
compreensão do que se passa com a vítima e não só com o réu, pela restauração dos direitos desta vítima, numa perspectiva de humanização de todos os sujeitos envolvidos no processo criminal. Alguns países como a África do Sul, Nova Zelândia e o Canadá já oferecem modelos de aplicação deste novo paradigma da Justiça, no qual os valores se inclinam para uma maior participação dos envolvidos nos casos. Tem-se, em particular nessa linha, uma ênfase em resoluções a partir da cooperação, numa perspectiva de restauração e inclusão das partes beligerantes, da responsabilização consciente do infrator e da ocupação central do processo pela vítima, possuindo aí papel e voz ativos (Maxwell \& Morris, 2004). Nas situações de violência, a Justiça Restaurativa vem preconizar que se valorizem os núcleos comunitários como forma de apoio e restauração da cidadania. Com relação a famílias em situação de vitimização sexual, a Justiça Restaurativa preconiza que a restauração dos direitos violados deve atuar em conexão efetiva com a rede de assistência social e de saúde para garantir encaminhamento de vítimas e infratores para atendimento específico, e aí se insere a necessidade do oferecimento de iniciativas como o GM (Pinto, 2005).

\section{MÉTODO}

Nossa opção para estudar este contexto de encaminhamento e atendimento, recaiu sobre o método qualitativo. A investigação foi realizada após 5 anos do estabelecimento da parceria. Esperamos que o melhor conhecimento sobre as expectativas e percepções dos profissionais que fazem os encaminhamentos para o GM possa gerar reflexões e mudanças na forma como a Justiça estabelece os elos de continuidade para a efetiva proteção de crianças e adolescentes na área de violência sexual.

O objetivo da pesquisa foi compreender quais sentidos foram e estão sendo produzidos nesta experiência do trabalho conjunto entre o profissional do setor psicossocial que entra em contato com a família antes da intervenção e a equipe que coordena, atende e supervisiona o oferecimento de uma intervenção terapêutica no GM. Em Spink (2000), diversos autores se propõem a discutir a produção de sentidos no cotidiano como objeto da Psicologia Social, sempre dentro do contexto histórico, e numa perspectiva de compartilhamento dos saberes já produzidos com outros saberes sendo produzidos. Essa confluência de sentidos, em suas contraposições e similaridades, é que pode nos indicar o resultado de uma avaliação geral, facili- tando-nos a apreensão de transformações e avanços no campo teórico-metodológico, no aspecto inovador da pesquisa do GM e nas dimensões íntimas de todos os sujeitos nela envolvidos.

Os participantes foram oito profissionais do setor psicossocial de um tribunal de justiça, sendo três assistentes sociais e cinco psicólogas - todas do sexo feminino, com idades entre 60 e 28 anos, atuando como profissional psicossocial entre 3 e 35 anos. Este setor realiza estudos com famílias que têm processos julgados principalmente em Varas Cíveis e excepcionalmente em Varas Criminais, possui em particular 12 profissionais mas consideramos como participantes somente oito deles em função de terem encaminhado famílias para atendimento no GM. A pesquisa foi aprovada pelo Conselho de Ética e Pesquisa da instituição universitária sob o registro número 027/2005 e conjuntamente recebeu a autorização do Juiz Corregedor do referido tribunal.

O instrumento utilizado foi uma entrevista semiestruturada realizada por bolsistas do projeto, no ambiente de trabalho destes profissionais. $\mathrm{O}$ instrumento foi elaborado de modo a responder às questões que julgamos primordiais de acordo com o seguinte argumento: como se dá o efeito da parceria e do atendimento no GM sobre estes profissionais, que possibilita que eles vejam a continuidade do estudo psicossocial realizado ainda na justiça e acompanhem a evolução do processo transformador das famílias em contexto psicossocial de intervenção? As questões foram: 1) O que significa para o setor psicossocial o convênio com a universidade, que permite o encaminhamento das famílias para esse grupo multifamiliar de abuso sexual? 2) Como tem sido acompanhada e avaliada essa parceria por parte do setor psicossocial? O que tem havido de positivo e de problemático em relação a esse convênio? 3) Quais os entraves, do ponto de vista da justiça, para a plena execução desse convênio? Quais benefícios o setor tem obtido? 4) A execução desse convênio tem levado à necessidade de alterar algum tipo de ação ou rotina do juiz, do promotor ou de outro setor do tribunal? 5) De alguma forma a aplicação desse convênio interfere na dinâmica interna (rotinas, decisões, metodologias) do judiciário? 6) Como essa experiência do GM de abuso sexual está sendo incorporada junto aos operadores da lei, de modo a interferir na criação ou reformulações de leis mais eficientes no que se refere ao abuso sexual de crianças e de adolescentes? 7) Qual tem sido a disponibilidade e sentimentos dos profissionais do setor para participa- 
rem dos procedimentos iniciais do grupo realizados no âmbito do tribunal?

A análise das informações foi realizada a partir da proposta de González Rey, denominada epistemologia qualitativa, que consiste em uma análise de conteúdo que revela um conhecimento construtivo-interpretativo (González Rey, 2005). Este autor propõe o conceito de "indicador" para "designar os elementos que adquirem significação graças à interpretação do pesquisador". O indicador pode ser um ou mais elementos retirados do texto produzido pelo informante. A interpretação do pesquisador e a integração do sentido comum, presente nos indicadores, constroem as "zonas de sentido", que se constituirão na produção do conhecimento. Trata-se de uma perspectiva de análise que nos possibilita identificar questões subjetivas assim como questões partilhadas socialmente.

\section{RESULTADOS E DISCUSSÃO}

As entrevistas foram organizadas e analisadas em três eixos de análise: a) O significado do Grupo Multifamiliar para os profissionais dos psicossociais; b) Dificuldades para a construção da complementariedade universidade-tribunal; e c) O Grupo Multifamiliar e as rotinas do Judiciário. Para cada um destes eixos, foram levantados os indicadores que propiciaram a construção das zonas de sentido que apresentamos a seguir.

\section{Eixo 1: 0 significado do Grupo Multifamiliar para os profissionais psicossociais}

\section{A parceria proporciona alívio para nossa preocupação}

A avaliação das condições emocionais e do estresse causado pelo atendimento a populações envolvidas com violência sexual é um item fundamental do planejamento de ações nesta área, nos países de língua inglesa (Moulden \& Firestone, 2007; Serran, Fernandez, Marshall \& Mann, 2003). É necessário conhecer e acompanhar estas reações porque a reincidência de violência está muito vinculada à efetividade das decisões dos profissionais responsáveis por terapias ou pelas ações de proteção relativas às vítimas.

Por isto é tão importante o reconhecimento de um certo alivio por parte das profissionais em poder encaminhar essas famílias que, na maioria das vezes, não possuem condições socioeconômicas para procurar um atendimento e, não estão esclarecidas quanto à necessidade de um acompanhamento terapêutico em determinados casos.
"A gente tinha uma inquietação muito grande de atender essas famílias, de perceber que há fortes indícios de abuso sexual e não tinha para onde encaminhar..." "...o espaço da universidade foi realmente um lugar para essas pessoas estarem conversando sobre isso tudo ... estarem entendendo mais o que é o abuso..." “...a gente fica satisfeita, como profissional de saúde, saber que essa família vai receber um atendimento digno ..."

Os técnicos relatam que se envolvem, profissional e emocionalmente com as famílias, trabalham com conteúdos delicados, buscam informações importantes para elaborar o estudo psicossocial e não podem, devido às limitações da própria instituição, oferecer um acompanhamento para a solução da problemática que foi identificada durante o estudo, surgindo os sentimentos de angústia relatados nas entrevistas.

"Significa um avanço em termos de parceria, tranquilidade para o técnico e melhor garantia de adesão da família à proposta” "... a gente vê o sofrimento, vê a angústia, vê o quanto essas situações afetam profundamente o ser humano ... então quando a gente sabe que vai ter um grupo multifamiliar é como se fosse um alivio".

A parceria com uma universidade representa um alívio para esses sentimentos, sobretudo por se tratar de casos graves de abuso sexual, tema que expõe as famílias e evidenciam sentimentos e conteúdos muito delicados.

“... Para o profissional é um alivio saber que a família vai ser acompanhada após a sentença do juiz ... saber o que vai acontecer, como está a criança ...Na maioria dos casos a gente não tem retorno nenhum".

Por outro lado, eles enfatizam a angústia que representa trabalhar com famílias com história de abuso sexual. Após vários encontros com a famílias, esta proximidade e o conhecimento de suas histórias de sofrimento, têm que encerrar os atendimentos, sem a perspectiva de um acompanhamento posterior para saber como as famílias estão (Costa, 2003). Em alguns casos, o risco de abuso continua pairando sobre a família. Habigzang, Azevedo, Koller e Machado (2006), em uma pesquisa sobre a efetividade da aplicação de medidas de proteção às vítimas de abuso sexual, mostram como os órgãos da Justiça (Ministério Público, Vara da Infância), ou ligado à Justiça (Conselho Tutelar), apresentam sérias deficiências no controle das medidas protetivas adotadas com relação a este problema, da denúncia aos encaminhamentos para 
atendimento. Muitos profissionais psicossociais têm consciência destas falhas e trabalham sob o estresse de saberem que seus esforços, na avaliação e elaboração de um relatório informativo sobre as condições de vulnerabilidade da criança/adolescente abusada, não terão uma resolubilidade satisfatória.

“... as famílias acabam que ficam esperando muito tempo e ai tem um caso que a criança fica sofrendo abuso. E aí? Vai continuar esse abuso? A gente não tem a menor certeza do que vai continuar acontecendo".

Correa, Labronici e Trigueiro (2009) avaliaram as emoções e sentimentos de enfermeiros que atendem adultos autores de violência, e mostram que estes profissionais são invadidos por sentimentos como angustia, impotência, consciência das limitações do trabalho, e principalmente questionamentos sobre sua própria subjetividade. A percepção do outro, que se constitui num veículo para percepção de si mesmo, é a principal ferramenta para dar conta do que se passa na relação entre o agressor e o profissional. Outras características são: sentir-se pouco resolutivo, medo do futuro, impotência por não conseguir controlar o meio ambiente da vítima. Estes autores chamam atenção para o fato de que os profissionais também se envolvem emocionalmente com as vítimas e ao entrarem em contato com a dor do agredido, entram em contato com sua própria dor, muitas vezes advindas de experiência de agressão também.

Neste sentido, torna-se fundamental que a dimensão reparadora se faça presente. Costa, Penso, Gramkow, Santana e Ferro (2003) enfatizam a importância da continuidade de um intervenção psicossocial fora do contexto jurídico, envolvendo profissionais da Psicologia e Serviço Social. Para as autoras o GM oferece um contexto clínico que proporciona uma intervenção psicossocial com resultados terapêuticos, porque adota um enfoque social/grupal com atenção à construção das redes sociais de seus participantes.

"Uma das famílias é catadora de lixo e as crianças todas estão correndo risco, na mesma situação”. “... essa população precisa de atendimento e não tem como recorrer a um psicólogo particular". "Para nós é um mediador importantíssimo, porque as famílias são de baixa renda e tem um grupo para elas estarem participando e isso é importante para elas e pra gente".

\section{A parceria é boa, mas é limitada...}

Apesar do reconhecimento da importância e necessidade da parceria, os sujeitos apontam a sua limitação, descrevendo como pontos negativos a pequena quantidade de vagas oferecidas pela parceria com a universidade, frente à grande demanda de casos que necessitam de atendimento e a dificuldade das famílias comparecerem aos encontros, pois a grande maioria não tem condições financeiras sequer para pagar as passagens.

"Nós temos uma falta muito grande de uma rede que funcione...". "Deveria haver mais grupos e com maior frequência..." "O ideal seria poder encaminhar todas essas famílias". "Problemático é essa questão da nossa demanda ser muito grande para o pouco serviço que vocês podem nos oferecer, que são poucos atendimentos".

A dificuldade de oferecimento de um fluxo de atendimento contínuo, característico de ambulatório público, se choca com os objetivos de uma instituição acadêmica, que procura privilegiar a pesquisa (precípuos da pós-graduação) e a formação de alunos (inerente à graduação). Como administrar estas diferenças? De fato, temos buscado nos manter em um patamar de excelência metodológica sem abrir mão de cuidados éticos na gerência desta interface, e discutindo uma posição de não assumir uma obrigação de escoar demanda. Mas... é o suficiente? Até o momento não temos uma resposta clara para esta pergunta e impasse. O GM é a resposta da universidade a uma parte do tripé já mencionado: a extensão. Reconhecemos que esta ação pode ser limitada pelo compromisso com as duas partes do tripé: ensino e pesquisa. Ocupamos uma posição de contribuição com atendimentos porém firmamos um lugar diferenciado de qualquer outro ambulatório de saúde mental, invocando uma perspectiva de semelhança com uma característica do Curso de Psicologia que é o oferecimento de atendimentos nas clínicas escolas. Como ação compensatória para esta nossa decisão, buscamos contribuir para esta interface, com treinamento a outros profissionais que queiram participar dos atendimentos nos GM, oferecendo consultoria ao setor psicossocial para a elaboração dos relatórios encaminhados ao juiz, sobre crianças e adolescentes violentados sexualmente.

\section{A comunicação precisa ocorrer continuamente entre pesquisadores e setor psicossocial}

Um outro aspecto apontado pelos sujeitos foi a necessidade de comunicação fluida entre a universidade e o setor psicossocial, que deve se traduzir por um compromisso com a discussão dos resultados de cada GM. 
"Os beneficios se estendem ao setor por aliviar a nossa angústia por termos para onde encaminhar esses casos".

A necessidade de comunicação e continuidade de contato é perfeitamente compreensível e necessária, e os profissionais sabem disso. Uma pesquisa foi realizada na Vara da Infância e da Juventude (VIJ) do TJDFT (Santos, 2007) sobre as condições que caracterizam as denúncias de abuso sexual. A justificativa para o melhor conhecimento destas condições encontra-se em Faleiros (2008): o abuso sexual é uma violência que precisa ser detida, sendo necessária sua urgente interdição. Daí a responsabilidade da Justiça participar do processo de significação da violência como violência e poder decretar a sua interrupção e restabelecer uma função de proteção à infância violada. A pesquisa de Santos (2007) objetivou realizar o acompanhamento do cumprimento das medidas protetivas determinadas pelo Juiz da VIJ às crianças e adolescentes e familiares envolvidos em situação de violência sexual. Tal acompanhamento visou ao conhecimento dos aspectos de resolubilidade das ações de enfrentamento da violência sexual, seja no âmbito da prevenção, da responsabilização e/ou de atendimento às vítimas e familiares. Os achados mostram que a maioria das instituições do sistema de garantia de direitos, a quem o tribunal faz os encaminhamentos, resume seu trabalho a outros encaminhamentos, gerando assim uma falsa ideia de resolução dos casos. Para estas famílias encaminhadas, que constroem expectativas de alívio para sua dor e sofrimento, resta o enfrentamento dos sentimentos de impotência e de vulnerabilidade. E para os profissionais que realizaram os encaminhamentos, angústia e frustração.

Esta pesquisa indicou que a revitimização ocorre na maioria dos casos pela falta de cumprimento das medidas protetivas, ou pelo descumprimento das medidas necessárias tais como: proteção da criança ou adolescente, processo de responsabilização e tratamento do abusador, dentre outras. A percepção dessas falhas gerou a criação do Centro de Referência para a Proteção Integral da Criança e do Adolescente em Situação de Violência Sexual, que tem função de acompanhar as famílias durante o seu percurso na rede institucional no intuito de se garantir que estes efetivamente tenham acesso aos atendimentos básicos de saúde, assistência social, entre outros, condições consideradas necessárias para o fortalecimento de suas competências e interrupção do ciclo de violência e revitimizações.
Após o término de cada GM, como já foi apontado no método, realizamos uma reunião com os profissionais que fizeram os encaminhamentos das famílias atendidas, para avaliação do quanto o GM pode estabelecer e/ou restabelecer condutas de proteção para as crianças e adolescentes. Na sequência de etapas, este ponto é chave pois, muitas vezes, se faz necessário alguma iniciativa do setor psicossocial no sentido de decretação de uma medida protetiva ou de uma sugestão, ao juiz, para interrupção do curso do processo e retomada posterior para nova avaliação.

"Há uma falha na comunicação dentro do Tribunal e não temos acesso ao Juiz". "É legal para a gente, saber o que aconteceu, saber como está a família". "Um ponto a ser corrigido, eu acho, é ter um feedback do que foi feito, quais os resultados obtidos, qual foi o andamento".

\section{Eixo 2: Dificuldades para a construção da complementaridade}

\section{A família necessita de apoio psicológico, mas não obrigada}

Para as entrevistadas o principal entrave se refere ao fato do Juiz não poder obrigar as famílias a participarem do GM, podendo haver somente a sugestão dos Magistrados para a participação das famílias. Esta observação se deve ao fato que esses magistrados atuam em Vara de Família, na qual a aplicação do Estatuto da Criança e do Adolescente (ECA) (Brasil, 1990) nem sempre se constitui em prática normativa. É preciso apontar aqui que este contexto vem mudando com celeridade. Em nossa experiência, existem decisões de proteção a famílias em situação de violência sexual que são estabelecidas de forma diferente, dependendo se são exaradas por Vara Cível ou por Vara da Infância. O artigo 129 do ECA, que prevê o encaminhamento para atendimento terapêutico, é uma medida protetiva que requer habilidades da instituição e dos profissionais para sua viabilidade e correto cumprimento porque estas famílias apresentam-se sem demanda.

"O Juiz não pode obrigar a família a fazer tratamento psicológico, ele pode recomendar, falar que a pessoa precisa fazer, mas não pode obrigar".

"Um dos entraves que eu vejo do ponto de vista da justiça é que o Juiz não tem aspecto legal para obrigar a família a ir. O Juiz pode determinar, "olha, você que ir, 
você vai", não pode". Se elas não quiserem ir não vão, porque o Juiz não tem como punir".

Para fins de atendimento terapêutico, é necessário identificar a diferença entre o contexto clínico e psicossocial, em função da existência da demanda. Acreditamos que no momento em que alguém procura um atendimento psicológico, na perspectiva da clínica, ele tem o "desejo" de falar das suas dificuldades, repensar sua forma de ser, provocar mudanças. No contexto psicossocial, trabalha-se com demandas de terceiros no que diz respeito ao comportamento e à forma de ser do sujeito, ou seja, é a Justiça que está mandando, ou é o juiz que mandou. Instituições como a Justiça, ou até mesmo a escola, é que estão demandando que a família apresente mudanças. O GM encontra-se como uma opção de atendimento psicossocial. No caso específico da pendência com a Justiça, estes sujeitos querem somente se ver livres destas dependências e poderão afirmar que aceitam terapia, ou que prometem buscar uma instituição clínica ou ainda assumem um compromisso, mesmo que não pretendam cumprilo. Entendemos que esta experiência da família ser orientada pelos profissionais do setor psicossocial pode ser vista como uma oportunidade para o aproveitamento do contexto jurídico como desencadeador de demandas, como contexto terapêutico sem ser clínico (Cirilo, 1994).

\section{O segredo de Justiça: proteção ou impedimento?}

Outro aspecto ao qual se referiram os sujeitos diz respeito ao caráter sigiloso dos processos de família, que ocorrem em segredo de justiça. Alguns profissionais se preocupam com este fato devido aos atendimentos ocorrerem em grupo, ou seja, as famílias teriam seus problemas expostos às outras famílias e não teriam, desta forma, assegurado o segredo das informações contidas no processo. Quanto a este ponto, parece que há certa confusão sobre o que se denomina como segredo de justiça e sobre a necessidade de se traçar com muito critério os limites entre os contextos jurídico e terapêutico. O segredo de justiça determina a proibição da divulgação do que se passa no processo crime, é o instrumento para se manter íntegro o desconhecimento de um fato (http://www.publico.clix.pt/ nos/livro_estilo/25-fichas-1.html). A prerrogativa do segredo de justiça diz respeito ao sigilo que deve ser mantido sobre as informações contidas no processo judicial para que os direitos fundamentais da vítima sejam preservados (http://www.dji.com.br/civil/sigilo_profissional.htm\#DEUS). Quando as famílias são encaminhadas para atendimento terapêutico fora do âmbito da justiça, é da responsabilidade e decisão delas como vão se comportar com relação aos fatos relacionados a seus sofrimentos. Esta dificuldade de limitação do espaço do contexto jurídico e do contexto de intervenção, associa-se ao fato de que estes sujeitos são profissionais inseridos no contexto das Varas de Família e, portanto têm uma função preservadora do discurso jurídico do segredo de Justiça. Dito de outra maneira, poderia ser este o fator que os levam a confundir os contextos no qual atuam, que é de avaliação das famílias, com o contexto do GM que é de intervenção terapêutica.

\footnotetext{
"Um dos entraves é a questão do sigilo de justiça, que é uma coisa que nos preocupa... pra gente fica meio dificil quando fala que vão juntar todas as famílias. A nossa preocupação é: como é que vai ficar resguardado o segredo de justiça?”. "... até onde a gente poderia encaminhar com o segredo de justiça, sem estar indo de encontro à lei?"”.
}

É necessário ainda se acrescentar que o GM tem como referencial teórico o conceito de rede social (Dabas, 1993) que se volta para a valorização da rede natural de pertencimento da família, e para o potencial de apoio e reestruturação vincular que esta rede pode oferecer. O GM, como proposta para as famílias em situação de abuso sexual, também se baseia na adoção deste conceito (vide referencial teórico do GM). Neste sentido, o GM encontra-se alinhado com as críticas decorrentes da pesquisa de Santos (2007), de que a construção de rede social de apoio às famílias é fator preponderante para a diminuição da revitimização. Portanto, enquanto contexto jurídico tem sentido a preservação do segredo de justiça, mas não mais no contexto terapêutico e/ou psicossocial de intervenção.

\section{Eixo 3: 0 Grupo Multifamiliar e as rotinas do Judiciário}

\section{O juiz e o Grupo Multifamiliar}

Existe, na opinião dos profissionais entrevistados, uma vontade, por parte de alguns Magistrados, de que o GM continue funcionando por intermédio da parceria.

\footnotetext{
“... assim como a gente tem uma angústia, eles (os juizes) também têm uma angústia de resolver a situação de uma forma positiva". "A gente tem recebido um apoio muito grande do Juiz, eles têm compreendido muito essa necessidade .... eles têm uma sensibilidade também pelo sentimento destas famílias principalmente quando
} 
se trata dessa questão de abuso, a gente percebe que eles também sofrem".

Os profissionais apontam para a importância atribuída à parceria entre a Justiça e a Universidade, que representa uma possibilidade de encaminhamento, já que existem poucas instituições públicas no Distrito Federal que atendam a esta problemática. Além disso, esta postura dos juízes está de acordo os preceitos de uma nova justiça, preocupada com os sujeitos por detrás dos processos. Podemos afirmar que se trata de um processo de "abertura dialógica" do sistema de justiça, que ao tomar consciência dos seus limites, numa compreensão mais ampla dos fatos sociais, passa a buscar parcerias para complementar o seu trabalho (Passos \& Penso, 2009). O GM também altera a rotina do encaminhamento dos processos de abuso sexual, no sentido que espera da universidade relatórios sobre os progressos conseguidos pelas famílias encaminhadas, principalmente no que diz respeito à concretização da proteção e cuidado das crianças e adolescentes vítimas de violência sexual.

Um último ponto a considerar é que o Juiz, em razão da representação da sua figura como autoridade, ao encaminhar as crianças e/ou adolescentes e suas famílias para o atendimento na universidade, atribui ao GM uma importância e uma significação muito maior, fazendo com que os participantes sintam-se cuidados em sua dificuldade e portanto demonstrem uma disponibilidade maior em participar.

\section{CONSIDERAÇÕES FINAIS}

Situamos a importância da discussão contida neste texto no âmbito da Justiça Restaurativa, que se define como um processo no qual "outras pessoas ou membros da comunidade afetados pelo crime, como sujeitos centrais, participam coletivamente na construção de soluções para a cura das feridas, dos traumas e perdas causados pelo crime" (Pinto, 2005, p. 3). O advento da Justiça Restaurativa representa uma provocação atual para que se faça verdadeiramente a justiça, que se dê atenção a ambos os sujeitos do delito (o autor do fato e a vítima) e que logre a reintegração social tanto da vítima como do infrator. É o que temos observado nas famílias em situações de violência sexual, e também o que esta parceria aponta: a possibilidade de uma ação prática que resulte em uma medida de implementação da Justiça Restaurativa. Por isto se reveste de importância esta oportunidade de podermos compreender melhor como podem ser significadas as relações entre os profissionais da justiça, que podem viabilizar a dimensão restaurativa da justiça (restauração dos direitos), e os profissionais que se colocam à disposição para esta mediação.

Esta interface Psicologia-Direito necessita ser conhecida e integrada às lides jurídica e psicológica, tanto nas instituições do Direito como nas instituições de atendimento psicológico. Na Justiça Restaurativa, os psicólogos e profissionais psicossociais, trabalhadores de instituições da comunidade, são indicados como os melhores mediadores ou facilitadores, porque possuem treinamento em habilidades de conversações construtivas e de restauração da dimensão compreensiva dos conflitos. Pinto (2005) indica que os núcleos de Justiça Restaurativa deverão trabalhar associados à rede de assistência social, preferencialmente em espaços comunitários, enfocando e valorizando as competências de pessoas e núcleos presentes neste contexto.

\section{REFERÊNCIAS}

Brasil. (1990). Estatuto da Criança e do Adolescente. Lei Federal n. 8.069, de 13 de julho de 1990. Brasília: Secretaria do Estado dos Direitos Humanos, Departamento da Criança e do Adolescente.

Cirilo, S. (1994). El cambio en los contextos no terapeuticos. Buenos Aires: Paidós.

Correa, M. E. C., Labronici, L. M., \& Trigueiro, T. H. (2009). Sentir-se impotente: Um sentimento expresso por cuidadores de vítimas de violência sexual. Revista Latino-Americana de Enfermagem, 17(3). Retirado em 20 de janeiro de 2010, de www.urp.usp.br/rlae

Costa, L. F., Penso, M. A, Gramkow, G., Santana, P., \& Ferro, V. S. (2003). Demandas judiciais: Resgatando a cidadania e o sofrimento em intervenções psicossociais. Em H. G. D. de Lima (Org.), Construindo caminhos para a intervenção psicossocial no contexto da Justiça (pp. 125-141). Brasília: TJDFT.

Dabas, E. N. (1993). Red de redes: Las prácticas de la intervención en redes sociales. Buenos Aires: Paidós.

Faleiros, V. P. (2008). Parar o abuso e desenvolver a proteção. Em L. F. Costa \& H. G. D. de Lima (Orgs.), Abuso sexual: A justiça interrompe a violência (pp. 159-170). Brasília: Liber.

Fávero, E. T., Melão, M. J. R., \& Jorge, M. R. T. (2005). O serviço social e a psicologia no judiciário: Construindo saberes, conquistando direitos. São Paulo: Cortez.

González Rey, F. (2005). Pesquisa qualitativa e subjetividade: Os processos de construção da informação. São Paulo: Thomson.

Habigzang, L. F., Azevedo, G. A., Koller, S. H., \& Machado, P. X. (2006). Fatores de risco e de proteção na rede de atendimento a crianças e adolescentes vítimas de violência sexual. Psicologia: Reflexão e Crítica, 19(3), 379-386.

Haley, J. (1998). Aprendendo e ensinando terapia (H. A. Mascarenhas, Trad.). Porto Alegre: Artmed.

Lima, H. G. D. (2003). Considerações finais. Em H. G. D. de Lima (Org.), Construindo caminhos para a intervenção psicossocial no contexto da Justiça (pp. 366-379). Brasília: TJDFT. 
Lane, S. T. M., \& Sawaia, B. B. (1995). La psicología social comunitaria en Brasil. Em E. Wiesenfeld \& E. Sánchez (Orgs.), Psicología social comunitaria: Contribuiciones latinoamericanas (pp. 69-112). Caracas: Fondo Editorial Tropykos.

Maxwell, G., \& Morris, A. (2004). Os modelos da justiça retributiva e da justiça restaurativa. Trabalho apresentado no Seminário sobre o Modelo Neozelandês de Justiça Restaurativa, Brasília.

Moreno, J. L. (1993). Psicoterapia de grupo e psicodrama (A. C. M. Cesarino Filho, Trad.) ( $2^{\mathrm{a}}$ ed.). Campinas: Psy.

Minuchin, P., Colapinto, J., \& Minuchin, S. (1999). Trabalhando com famílias pobres (M. F. Lopes, Trad.). Porto Alegre: Artes Médicas.

Moulden, H. M., \& Firestone, P. (2007). Vicarious traumatization: The impact on therapists who work with sexual offenders. Trauma, Violence \& Abuse, 8(1), 67-83.

Passos, L. M. X., \& Penso, M. A. (2009). O papel da comunidade na aplicação e execução da justiça penal. Brasília: Escola Superior do Ministério Público da União.

Penso, M. A., Gusmão, M. M., \& Ramos, M. E. C. (2003) Oficina de ideias: Uma experiência precursora com adolescentes em conflito com a lei pelo envolvimento com drogas. Em M. F. O. Sudbrack, M. I. G. Conceição, E. M. F. Seidl \& M. T. Silva (Orgs.), Adolescentes e drogas no contexto da justiça (pp. 191202). Brasília: Plano.

Penso, M. A., Ramos, M. E. C., \& Gusmão, M. M. (2005). O pai de botas: Violência intrafamiliar sofrida por adolescentes envolvidos em atos infracionais e com drogas. Em L. F. Costa \& T. M. C. Almeida (Orgs.), Violência no cotidiano: Do risco à proteção (pp. 166-184). Brasília: Universa/Líber.

Pinto, R. S. G. (2005). Justiça restaurativa: É possível no Brasil? Retirado em 28 de junho de 2007, de http://www.idcb.org.br/ documentos/artigos3001/art justicaresatu.doc

Ramos, M., \& Shine, S. K. (1999). A família em litígio. Em M. Ramos (Org.), Casal e família como paciente (pp. 95-122). São Paulo: Escuta.
Ribeiro, R. (2003). Reflexões pós modernas acerca do psicólogo no contexto da Justiça. Em H. G. D. de Lima (Org..), Construindo caminhos para a intervenção psicossocial no contexto da justiça (pp. 46-60). Brasília: TJDFT.

Santos, V. A. (2007). Projeto piloto centro de referência sobre violência sexual contra crianças e adolescentes. Retirado em 21 de fevereiro de 2008, de http://www.tjdft.gov.br/tribunal/vij/ projetos/relatorio $\% 20$ projeto $\% 20$ piloto.pdf

Santos, B. S. (1999). Um discurso sobre as ciências (11 $1^{\mathrm{a}}$ ed.). Porto: Afrontamento.

Serran, G., Fernandez, Y., Marshall, W. L., \& Mann, R. E. (2003). Process issues in treatment: Application to sexual offender programs. Professional Psychology: Research and Practice, 54(4), 368-374.

Spink, M. J. (Org.) (2000). Práticas discursivas e produção de sentidos no cotidiano: Aproximações teóricas e metodológicas ( $2^{a}$ ed.). São Paulo: Cortez.

Sudbrack, M. F. O (2003). Da obrigação à demanda, do risco à proteção e da dependência à liberdade: Abordagem da drogadição de adolescentes em conflito com a lei. Em M. F. O. Sudbrack, M. I. G. Conceição, E. M. F. Seidl \& M. T. Silva (Orgs), Adolescentes e drogas no contexto da justiça (pp. 191202). Brasília: Plano.

Sluzki, C. E. (1996). Violência familiar e violência política: Implicações terapêuticas de um modelo geral. Em D. F. Schnitman (Org.), Novos paradigmas, cultura e subjetividade (J. H. Rodrigues, Trad.) (pp. 228-243). Porto Alegre: Artes Médicas.

Xaud, G. M. B. (2000). Os desafios da intervenção psicológica na promoção de uma nova cultura de atendimento do adolescente em conflito com a lei. Em L. M. T. Brito (Org.), Temas em psicologia jurídica (pp. 87-102). São Paulo: Relume Dumará.

Recebido: $12 / 08 / 2007$ Última revisão: 13/04/2010 Aceite final: $20 / 04 / 2010$

\section{Sobre os autores:}

Maria Alexina Ribeiro: Psicóloga, Terapeuta Conjugal e Familiar, Terapeuta Sexual. Doutora em Psicologia Clínica pela Universidade de Brasília. Professora no Curso de Graduação e no Programa de Pós-graduação em Psicologia da Universidade Católica de Brasília UCB. Endereço eletrônico: alexina@solar.com.br.

Liana Fortunato Costa: Psicóloga, Terapeuta Familiar e Psicodramatista. Doutora em Psicologia Clínica pela Universidade de São Paulo. Docente Permanente do Programa de Pós-graduação em Psicologia Clínica e Cultura - PSICC - UnB. Endereço eletrônico: lianaf@terra.com.br

Maria Aparecida Penso: Psicóloga, Terapeuta Conjugal e Familiar, Psicodramatista. Doutora em Psicologia Clínica pela Universidade de Brasília. Professora no Curso de Graduação e no Programa de Pós Graduação em Psicologia da Universidade Católica de Brasília UCB. Endereço eletrônico: penso@ucb.br.

Tânia Mara Campos de Almeida: Antropóloga, Doutora em Antropologia pela Universidade de Brasília. Pós-doutorado em Representações Sociais pela perspectiva da Psicossociologia - EHESS/Paris. Professora no Curso de Graduação e no Programa de Pós-graduação em Psicologia da Universidade Católica de Brasília. Endereço eletrônico: taniamaraca@yahoo.com.br.

Heron Flores Nogueira: Psicólogo pela Universidade Católica de Brasília - Endereço eletrônico: heronfn@uol.com.br. 